\title{
Monensin by Fat Interactions on Trans Fatty Acids in Cultures of Mixed Ruminal Microorganisms Grown in Continuous Fermentors Fed Corn or Barley
}

\author{
T. C. Jenkins, ${ }^{*}$ V. Fellner, $\dagger$ and R. K. McGuffey‡ \\ *Department of Animal \& Veterinary Sciences, \\ Clemson University, Clemson, SC 29634 \\ †Department of Animal Science, \\ North Carolina State University, Raleigh 27695 \\ łElanco Animal Health, Indianapolis, IN 46240
}

\begin{abstract}
In previous studies, monensin ( $\mathrm{M})$ and unsaturated plant oils independently increased trans fatty acid concentrations in cultures of mixed ruminal microorganisms. This study was conducted to determine if combining $\mathrm{M}$ with plant oil yielded interactions on trans fatty acid concentrations in cultures of mixed ruminal microorganisms or their effects were additive. Four continuous fermentors were fed $14 \mathrm{~g}$ of dry feed per day (divided equally between two feedings), consisting of alfalfa hay pellets $(30 \%$ of $\mathrm{DM})$ and either a high corn $(\mathrm{HC})$ or a high barley (HB) concentrate $(70 \%$ of $\mathrm{DM})$ in each of two fermentors. Within each grain type, one fermentor was supplemented with M ( $25 \mathrm{ppm})$, and the other fermentor was supplemented with 5\% soybean oil (SBO) during $\mathrm{d} 5$ to 8 . Monensin and SBO were added together in all fermentors during d 9 to 12 . Samples were taken at $2 \mathrm{~h}$ after the morning feeding on the last day of each period and analyzed for fatty acids by gas-liquid chromatography. A second run of the fermentors followed the same treatment sequence to give additional replication. Average $\mathrm{pH}$ across all treatments was 6.15, which was reduced by $\mathrm{M}$ but not affected by SBO. Monensin reduced the ratio of acetate to propionate (A:P), which averaged 2.03 across all treatments; fat decreased A:P in cultures not receiving $\mathrm{M}$ but increased it in the presence of $\mathrm{M}$. Monensin and SBO altered the concentration of several trans fatty acids, but the only interaction was a grain $\times \mathrm{M} \times \mathrm{SBO}$ interaction for trans$10 \mathrm{C} 18: 1$. The increase in trans-10 C18:1 by the $\mathrm{M}$ and SBO combination exceeded the sum of increases in trans-10 C18:1 for each individual feed additive, but only for HB. For the HC diet, M increased trans-10 C18:1 more than fat alone and more than the $\mathrm{M}$ and SBO combination. The results of this study show that
\end{abstract}

Received July 3, 2002.

Accepted August 16, 2002.

Corresponding author: T. C. Jenkins; e-mail: tjnkns@Clemson.edu.
$\mathrm{M}$ and SBO effects are additive for all trans FA except for trans-10 C18:1. In the case of trans-10 C18:1, M and SBO interacted to give higher trans-10 C18:1 concentrations in ruminal contents than would be expected simply by adding their individual effects, but only for HB. Because some trans fatty acid isomers have been associated with milk fat depression in dairy cows, these results suggest more severe depressions in milk fat content when cows are fed $\mathrm{M}$ along with unsaturated plant oils.

(Key words: monensin, soybean oil, trans fatty acid, ruminal microorganism, continuous culture)

Abbreviation key: A:P = acetate to propionate ratio, CLA = conjugated linoleic acid, FA = fatty acids, SBO = soybean oil,

\section{INTRODUCTION}

Trans fatty acids (FA) are produced as intermediates of FA biohydrogenation by ruminal microorganisms and are linked to milk fat depression in dairy cattle (Griinari et al., 1998). Bessa et al. (2000) identified three factors that affected the concentration of trans $\mathrm{C} 18: 1$ isomers produced in the rumen:1) the concentration of unsaturated $\mathrm{FA}, 2$ ) rumen $\mathrm{pH}$, and 3) ionophores. The concentration of unsaturated FA in the rumen can be manipulated by adjusting the amount and source of added fat. Trans C18:1 concentration in ruminal contents of Holstein cows steadily increased as the percentage of soybean oil (SBO) in the diet increased from 0 to 8\% (Bateman and Jenkins, 1998). Also, trans C18:1 flow to the duodenum of cows can be enhanced by increasing the ratio of unsaturated to saturated FA in the fat supplement (Pantoja et al., 1996). Feeding unsaturated plant oils also increases the ruminal and milk concentrations of conjugated linoleic acid (CLA) that have one or more trans double bonds, including some isomers that are highly effective at causing milk fat depression (Baumgard et al., 2000). 
Ionophores disrupt ruminal biohydrogenation similar to unsaturated fat supplements. Higher concentrations of linoleic acid, trans C18:1, and CLA were maintained in continuous cultures of ruminal bacteria following infusion of monensin, nigericin, or tetronasin (Fellner et al., 1997). Feeding monensin had similar effects on enhancing linoleic acid and trans FA in milk of lactating cows, and also caused a reduction in milk fat percentage (Sauer et al., 1998). According to Van Nevel and Demeyer (1995), ionophores and other antimicrobials act primarily to inhibit lipolysis, thus reducing the formation of a free carboxyl group that is a requirement for subsequent hydrogenation of double bonds.

This study was conducted to determine if combining monensin with SBO yielded interactions on trans FA concentrations in cultures of mixed ruminal microorganisms or if their effects were additive. A second objective was to identify how monensin and plant oil affected the double bond position of trans C18:1 isomers produced in continuous cultures of mixed ruminal microorganisms.

\section{MATERIALS AND METHODS}

\section{Fermentor Conditions}

Whole ruminal contents were taken from a ruminally-fistulated cow fed a predominantly forage diet, transported in vacuum containers to the lab, and filtered through double-layered cheesecloth prior to incubation in the fermentors. Approximately $700 \mathrm{ml}$ of the strained ruminal fluid were transferred into each of the four fermentors. Culture vessels used in this study were an all glass, closed system type with a continuous independent flow of liquid and particulate matter. Air leak into the fermentor is avoided by 1 ) rubber seals and 2) a continuous flow of $\mathrm{CO}_{2}(20 \mathrm{ml} / \mathrm{min})$ that maintains anaerobic conditions as well as a positive internal pressure. Artificial saliva was delivered using a precision pump set at a flow rate of $0.73 \mathrm{ml} / \mathrm{min}$ resulting in a fractional dilution rate of $6.8 \% / \mathrm{h}$ as described by Fellner et al. (1995). The $\mathrm{pH}$ was monitored during the entire duration of the experiment. The temperature of ruminal cultures was maintained at $39^{\circ} \mathrm{C}$ by a circulating water bath. Culture contents were mixed continually at $10 \mathrm{rpm}$. Fermentors were allowed to stabilize for 4 $\mathrm{d}$ to respective diets prior to the administration of additives.

\section{Diets and Additives}

A total of $14 \mathrm{~g}$ of feed (DM basis) was placed in each fermentor daily in two equal portions at 0800 and 1500 h. Diets consisted of a pelleted concentrate mix and
Table 1. Formulation of concentrate mix.

\begin{tabular}{llc}
\hline & Mix 1 & Mix 2 \\
\hline Corn, ground & 70.0 & - \\
Barley, ground & - & 73.0 \\
SBM, 49\% CP & 27.0 & 24.0 \\
Premix $^{1}$ & 3.0 & 3.0 \\
\hline
\end{tabular}

${ }^{1}$ Consisted of $0.8 \%$ limestone; $0.4 \%$ salt; $0.09 \%$ magnesium oxide; $0.68 \%$ sodium bicarbonate; $0.06 \%$ potassium chloride and $0.12 \%$ vitamin trace mineral mix which provided per kilogram of diet: $66 \mathrm{mg}$ of S, $46 \mathrm{mg}$ of $\mathrm{Zn}, 46 \mathrm{mg}$ of $\mathrm{Mn}, 14 \mathrm{mg}$ of $\mathrm{Cu}, 11.6 \mathrm{mg}$ of $\mathrm{Fe}, 0.8 \mathrm{mg}$ of I, $0.7 \mathrm{mg}$ of Co, $0.3 \mathrm{mg}$ of Se, $7075 \mathrm{IU}$ of vitamin A, $1769 \mathrm{IU}$ of vitamin $\mathrm{D}$, and $21 \mathrm{IU}$ of vitamin $\mathrm{E}$.

alfalfa hay (70:30, DM basis). Two concentrate mixes were formulated using either corn or barley as the grain source. Soybean meal $(49 \% \mathrm{CP})$ was included in both mixes to keep the crude protein levels similar. Both mixes included a vitamin and mineral premix (Table 1). The FA content of alfalfa hay was $2.3 \%$ and that of the concentrate mix 1 and 2 was 1.0 and $0.8 \%$, respectively. Total FA content of soybean oil was $88.1 \%$ and consisted predominantly of C18:2 (55\%) and cis C18:1 $(22.5 \%)$.

Two fermentors received the high corn diet and the other two fermentors received the high barley diet. After $4 \mathrm{~d}$ of adaptation to the respective diets, one fermentor within each grain source received monensin (25 ppm of diet DM) and the other received supplemental SBO (5\% of diet DM) during d 5 to d 8 (Table 2). Both monensin and SBO were included in all fermentors during $d 9$ to 12 . The same treatment protocol was repeated a second time to give additional replication. Therefore, the experiment consisted of four continuous fermentors operated for two 12-d runs. Each 12-d run was divided into three periods that included:

Period 1: adaptation to diet for $4 \mathrm{~d}$.

Period 2: $25 \mathrm{ppm}$ monensin for $4 \mathrm{~d}$ or 5\% SBO for $4 \mathrm{~d}$.

Period 3: $25 \mathrm{ppm}$ monensin for $4 \mathrm{~d}$ and 5\% SBO for $4 \mathrm{~d}$.

Monensin was purchased from Sigma Chemical Co. (St. Louis, MO), and SBO (Wesson brand) was purchased at a local grocery store. Samples for VFA, ammonia, $\mathrm{pH}$, and methane were taken each day of the experiment at $2 \mathrm{~h}$ after the morning feeding. Analysis of VFA was done by GLC as described by Fellner et al. (1997). Ammonia-N was measured using a colorimetric assay (Beecher and Whitten, 1970). Headspace gas samples were obtained in gas tight syringes and analyzed for methane by GLC (Fellner et al., 1997).

A separate sample (5-ml) of the mixed cultures was taken on the last day of each period at $2 \mathrm{~h}$ after the 
Table 2. Treatment protocol.

\begin{tabular}{lllll}
\hline Culture & Diet & $(\mathrm{d} 1$ to 4$)$ & Additive (d 5 to 8) & Additive (d 9 to 12) \\
\hline 1 & Corn & $-\mathrm{M}-\mathrm{F}^{1}$ & $+\mathrm{M}-\mathrm{F}$ & $+\mathrm{M}+\mathrm{F}$ \\
2 & Corn & $-\mathrm{M}-\mathrm{F}$ & $-\mathrm{M}+\mathrm{F}$ & $+\mathrm{M}+\mathrm{F}$ \\
3 & Barley & $-\mathrm{M}-\mathrm{F}$ & $+\mathrm{M}-\mathrm{F}$ & $+\mathrm{M}+\mathrm{F}$ \\
4 & Barley & $-\mathrm{M}-\mathrm{F}$ & $-\mathrm{M}+\mathrm{F}$ & $+\mathrm{M}+\mathrm{F}$ \\
\hline \multicolumn{2}{l}{${ }^{1}$ Additives were monensin at $0(-\mathrm{M})$ or $25 \mathrm{ppm}(+\mathrm{M})$, and SBO at $0(-\mathrm{F})$ or $5 \%(+\mathrm{F})$ of the dietary DM. }
\end{tabular}

morning feeding and frozen for analysis of long-chain fatty acids. The frozen samples were freeze-dried, methylated (Kramer et al., 1997), and then analyzed for FA composition by GLC. Fatty acid methyl esters were separated on a $100-\mathrm{m} \times 0.25-\mathrm{mm} \times 0.2-\mu \mathrm{m}$ film thickness CP-Sil 88 capillary column (Chrompack, Middleburg, The Netherlands). Each sample was run twice as described by Griinari et al. (1998), first using a temperature gradient $\left(70\right.$ to $240^{\circ} \mathrm{C}$ ) to determine total fatty acid profile and then isothermally $\left(160^{\circ} \mathrm{C}\right)$ to separate cis and trans mononenes. Chromatograms of trans FA were similar to the chromatographs reported by Griinari et al. (1998), which provided a basis for peak identification. Further verification of peak identity was established by comparison of peak retention times to known standards.

\section{Statistical Analyses and FA Terminology}

Fermentation data from the last $2 \mathrm{~d}$ of each treatment period and FA data from d 4 of each period were analyzed according to a randomized complete block design using the Proc Mixed procedure of SAS (1999). Sources of variation in the model included grain source, monensin, SBO, and all possible interactions tested against residual error.

Fatty acids are designated by number of carbons:number of double bonds. Unsaturated FA identified as C18:1, C18:2, and C18:3 refer to oleic, linoleic, and linolenic acids, respectively. Trans FA are identified according to their positional (location of double bonds) and geometrical (cis or trans) isomers.

\section{RESULTS AND DISCUSSION}

Total VFA concentrations ranged between 54 to 56 $\mathrm{mM}$, and A:P ranged from 1.7 to 2.4 in the fermentors across all treatments (Table 3 ). These numbers were lower than usually reported in continuous cultures. For instance, total VFA concentrations and A:P were 104.3 and 2.71 (Vasquez-Anon et al., 2001), 81.2 and 3.0 (Fellner et al., 1995), and 76.1 and 3.0 (Fellner et al., 1997) in continuous cultures with no additives. In these previous studies, feeding rates and fiber concentration of the diets were generally higher $(50 \%$ forage compared to
$30 \%$ forage in the present study). The lower forage content in this study did not appear to cause an acidity problem in the cultures, as $\mathrm{pH}$ values remained within normal limits, i.e., 6.0 to 6.3.

Compared to corn, fermentation of the barley diet increased $(P<0.05)$ total VFA, isobutyrate, isovalerate, and ammonia concentrations, but grain source had no effect on $\mathrm{pH}$ (Table 3). Monensin addition did not affect total VFA concentration, but it increased $(P<0.05)$ valerate concentration and reduced $(P<0.05)$ isobutyrate, $\mathrm{pH}$, and ammonia. Adding SBO had no effect on total VFA, ammonia, or $\mathrm{pH}$, but it increased $(P<0.05)$ valerate concentration from 2.0 to $2.6 \mathrm{~mol} / 100 \mathrm{~mol}$. Digestibility, calculated as the g feed used for VFA plus methane per $100 \mathrm{~g}$ dry feed added to the fermentors each day, was not affected by grain source, monensin, or SBO.

There were several treatment interactions affecting acetate, propionate, and butyrate concentrations. Monensin increased $(P<0.05)$ acetate concentration in the culture contents (from 55.2 to $58.9 \mathrm{~mol} / 100 \mathrm{~mol}$ ) when the grain source was corn, but decreased $(P<0.05)$ acetate concentration (from 55.4 to $50.3 \mathrm{~mol} / 100 \mathrm{~mol}$ ) when the grain source was barley. Monensin decreased $(P<0.05)$ butyrate concentrations for both corn (from 14.4 to $10.9 \mathrm{~mol} / 100 \mathrm{~mol}$ ) and barley (from 16.0 to 8.3 $\mathrm{mol} / 100 \mathrm{~mol}$ ), but the drop was greater for the barley diet. Monensin by SBO interactions were observed for propionate and butyrate. Propionate concentration increased $(P<0.05)$ when SBO was added without monen$\sin$ (from 22.4 to $26.9 \mathrm{~mol} / 100 \mathrm{~mol}$ ), but its concentration decreased $(P<0.05)$ when SBO was added with monensin (from 35.3 to $30.5 \mathrm{~mol} / 100 \mathrm{~mol}$ ). Butyrate concentration decreased $(P<0.05)$ when SBO was added without monensin (from 16.5 to $13.9 \mathrm{~mol} / 100 \mathrm{~mol}$ ), but it was not affected by SBO when added with monensin (9.0 and $10.2 \mathrm{~mol} / 100 \mathrm{~mol}$ ).

Overall, monensin had a greater effect on reducing $\mathrm{A}: \mathrm{P}$ when the diet contained barley instead of corn, as shown by the grain source by monensin interaction in Figure 1. Also, adding SBO reduced $(P<0.05) \mathrm{A}: \mathrm{P}$ and methane production but only in the absence of monensin. When monensin was present, SBO had no effect on $\mathrm{A}: \mathrm{P}$ and methane (Figure 1). Unsaturated plant oils, such as SBO, typically interfere with ruminal fermenta- 
Table 3. Main effects of grain source, monensin, and soybean oil on VFA, methane, ammonia, and digestibility in continuous cultures of mixed ruminal microbes.

\begin{tabular}{|c|c|c|c|c|c|c|c|}
\hline & \multicolumn{2}{|c|}{ Grain } & \multicolumn{2}{|c|}{ Monensin, ppm } & \multicolumn{2}{|c|}{ Soybean oil, \% } & \multirow[b]{2}{*}{ SEM } \\
\hline & Corn & Barley & 0 & 25 & 0 & 5 & \\
\hline $\begin{array}{l}\text { VFA, mM } \\
\mathrm{mol} / 100 \mathrm{~mol}\end{array}$ & $53.5^{*}$ & 56.2 & 55.7 & 54.0 & 54.5 & 55.2 & 2.4 \\
\hline Acetate $(\mathrm{A})^{1}$ & 57.1 & 52.9 & 55.3 & 54.6 & 56.9 & 53.0 & 1.5 \\
\hline Propionate $(\mathrm{P})^{2}$ & 29.4 & 28.2 & $24.6^{*}$ & 32.9 & 28.9 & 28.7 & 1.2 \\
\hline Butyrate $^{1,2}$ & 12.6 & 12.1 & $15.2^{*}$ & 9.6 & 12.8 & 12.0 & 1.2 \\
\hline Isobutyrate & $0.6^{*}$ & 0.8 & $0.8^{*}$ & 0.6 & 0.7 & 0.7 & 0.1 \\
\hline Valerate & 2.2 & 2.4 & $1.9 *$ & 2.6 & $2.0 *$ & 2.6 & 0.2 \\
\hline Isovalerate & $1.7^{*}$ & 3.5 & 2.2 & 3.0 & 2.2 & 3.0 & 0.4 \\
\hline $\mathrm{A}: \mathrm{P}^{1,2}$ & 1.99 & 2.08 & $2.37 *$ & 1.70 & 2.12 & 1.94 & 0.20 \\
\hline $\mathrm{pH}$ & 6.14 & 6.16 & $6.26^{*}$ & 6.04 & 6.15 & 6.15 & 0.04 \\
\hline Methane, $\mathrm{mmol} / \mathrm{d}^{2}$ & $12.2^{*}$ & 14.9 & $15.9^{*}$ & 11.3 & 13.8 & 13.3 & 0.9 \\
\hline Ammonia-N, mg/dl & $16.0^{*}$ & 22.4 & $20.7^{*}$ & 17.8 & 19.6 & 18.9 & 2.1 \\
\hline Digestibility, $\%^{3}$ & 41.3 & 42.2 & 43.5 & 40.3 & 42.5 & 41.1 & 3.0 \\
\hline
\end{tabular}

*Main effect $(P<0.05)$.

${ }^{1}$ Grain $\times$ monensin interaction $(P<0.05)$.

${ }^{2}$ Monensin $\times$ soybean oil interaction $(P<0.05)$.

${ }^{3}$ Calculated as $\mathrm{g}$ feed used for VFA + methane per $100 \mathrm{~g}$ of dry feed added per day.
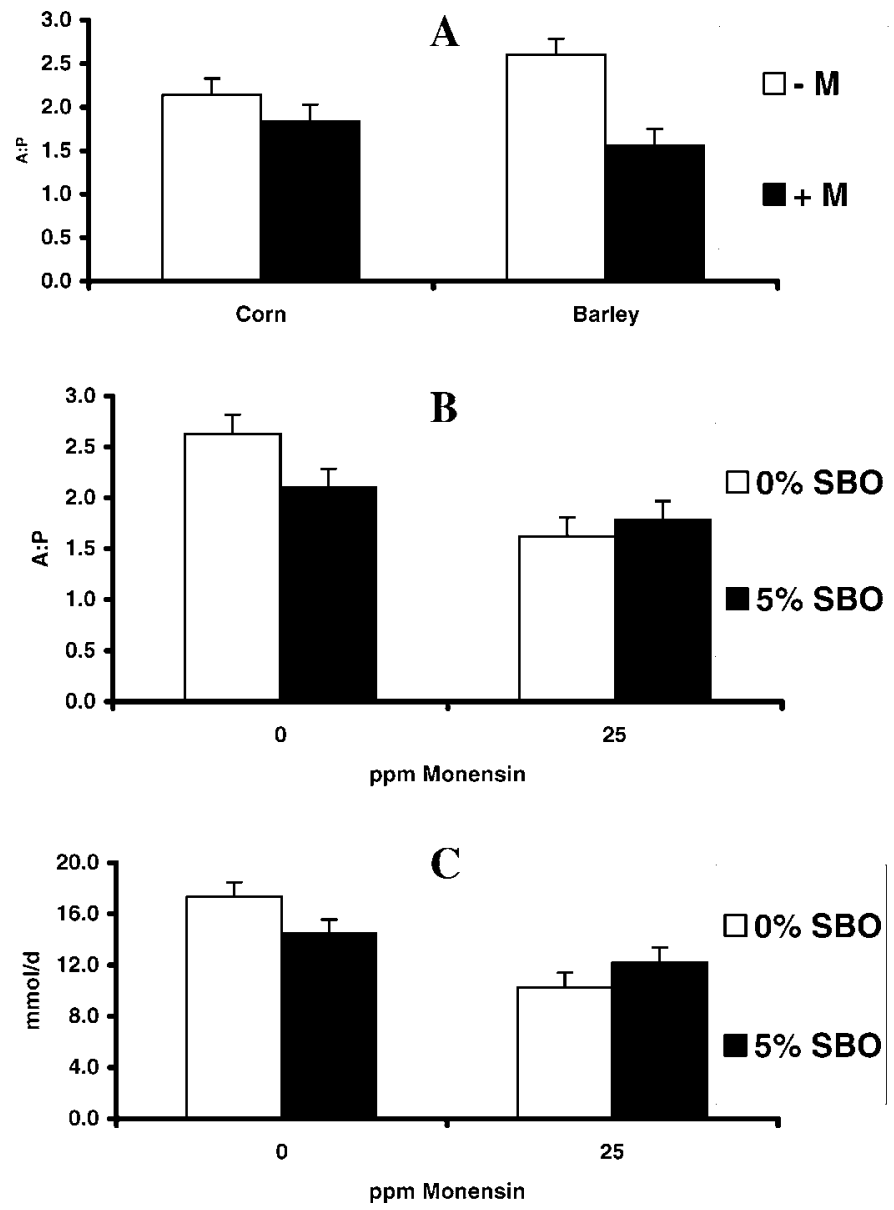

Figure 1. A) The grain source by monensin (M) interaction on acetate to propionate ratio $(\mathrm{A}: \mathrm{P})$ in continuous fermentors, and the monensin by soybean oil (SBO) interaction on B) A:P and C) methane production. Error bars are pooled SEM. tion, causing a drop in A:P and methane, similar to the effects of ionophores. This interaction suggests that ruminal microorganisms already suppressed by the action of one antimicrobial agent, such as an ionophore, are less susceptible to the suppressive effects of a second antimicrobial agent, such as unsaturated FA.

Fatty acid composition of the fermentor contents $2 \mathrm{~h}$ after feeding on $\mathrm{d} 4$ of each period is shown in Table 4. Interactions occurred for C16:0, C18:0, C18:1, and $\mathrm{C} 18: 2$. The proportion of $\mathrm{C} 18: 3$ was not affected by grain source or monensin, but it was reduced $(P<0.05)$ by the addition of SBO. Adding SBO to the fermentors also reduced $(P<0.05)$ the proportion of $\mathrm{C} 16: 0$ in the culture contents, especially when the grain source was barley (Figure 2A). The proportion of $\mathrm{C} 18: 0$ was reduced $(P<$ 0.05 ) by monensin but only when the fermentors were not supplemented with SBO. Based on the lower C18:0 (Figure 2B) and higher total trans-C18:1 (Table 4) concentrations in the fermenters, it appears that monensin interfered with the terminal step of biohydrogenation where trans mononenes are converted to stearic acid.

Grain source $\times$ monensin $\times$ SBO interactions for C18:1 and C18:2 are shown in Figure 3. When the fermentors were fed the corn diet with no additives, the proportions of $\mathrm{C} 18: 1$ and $\mathrm{C} 18: 2$ were higher than when they were fed the barley diet. In the case of C18:1, this reflects differences in the FA composition of the two grain sources. The corn used in this study contained higher C18:1 than the barley source (30.7 and $14.2 \%$ of the total FA, respectively). However, the C18:2 content of the two grain sources were similar (51.9 and $54.9 \%$ of total FA for corn and barley, respectively), suggesting that the lower concentration of C18:2 for the barley diet could be attributed to enhanced biohy- 
Jenkins et al.

Table 4. Main effects of grain source, monensin, and soybean oil on major FA in continuous cultures of mixed ruminal microbes.

\begin{tabular}{|c|c|c|c|c|c|c|c|}
\hline & \multicolumn{2}{|c|}{ Grain } & \multicolumn{2}{|c|}{ Monensin, ppm } & \multicolumn{2}{|c|}{ Soybean oil, \% } & \multirow[b]{2}{*}{ SEM } \\
\hline & Corn & Barley & 0 & 25 & 0 & 5 & \\
\hline & & & & $\mathrm{g} / 100 \mathrm{~g}$ & & & \\
\hline $\mathrm{C} 16: 0^{1}$ & $18.5^{*}$ & 21.6 & 20.2 & 19.9 & $22.0 *$ & 18.1 & 0.3 \\
\hline $\mathrm{C} 18: 0^{2}$ & $18.2^{*}$ & 24.1 & $24.7^{*}$ & 17.7 & 22.2 & 20.1 & 1.5 \\
\hline C18: $1^{1,2,3}$ & $13.6^{*}$ & 11.6 & $13.0^{*}$ & 12.3 & $13.2^{*}$ & 12.0 & 0.3 \\
\hline $\mathrm{C} 18: 2^{3}$ & $17.1^{*}$ & 13.9 & $16.3^{*}$ & 14.7 & $18.8^{*}$ & 12.2 & 0.7 \\
\hline C18:3 & 1.8 & 2.0 & 1.8 & 2.1 & $2.3^{*}$ & 1.6 & 0.2 \\
\hline \multicolumn{8}{|c|}{ TransC18:1 } \\
\hline t6 & 0.61 & 0.67 & 0.53 & 0.75 & 0.64 & 0.64 & 0.10 \\
\hline $\mathrm{t} 10^{3}$ & 14.1 & 12.2 & $9.5^{*}$ & 16.9 & $4.5^{*}$ & 21.8 & 1.1 \\
\hline t11 & $9.9^{*}$ & 7.5 & 7.7 & 9.7 & $9.9 *$ & 7.5 & 0.6 \\
\hline $\mathrm{t} 12$ & 0.39 & 0.40 & 0.33 & 0.46 & $0.19^{*}$ & 0.59 & 0.10 \\
\hline Total & $25.0^{*}$ & 20.8 & $18.1^{*}$ & 27.7 & $15.3^{*}$ & 30.5 & 1.2 \\
\hline \multicolumn{8}{|c|}{ Conjugated linoleic acids } \\
\hline c9t11 & $0.42 *$ & 0.11 & 0.25 & 0.27 & 0.31 & 0.22 & 0.03 \\
\hline $\mathrm{t} 10 \mathrm{c} 12$ & 0.07 & 0.13 & 0.10 & 0.11 & $0.03 *$ & 0.18 & 0.03 \\
\hline t9t11 & 0.21 & 0.23 & $0.26 *$ & 0.18 & 0.23 & 0.21 & 0.03 \\
\hline Total & $0.70 *$ & 0.47 & 0.61 & 0.56 & 0.56 & 0.62 & 0.06 \\
\hline Other & 5.0 & 5.6 & 5.4 & 5.2 & $5.7^{*}$ & 4.9 & 0.3 \\
\hline
\end{tabular}

*Main effect $(P<0.05)$.

${ }^{1}$ Grain $\times$ soybean oil interaction $(P<0.05)$.

${ }^{2}$ Monensin $\times$ soybean oil interaction $(P<0.05)$.

${ }^{3}$ Grain $\times$ monensin $\times$ soybean oil interaction $(P<0.05)$.

drogenation. Higher rates of starch fermentation for barley compared to corn could account for this if it contributed to lower $\mathrm{pH}$ in the rumen. Low ruminal $\mathrm{pH}$ inhibits lipolysis and biohydrogenation (Van Nevel and Demeyer, 1996), leading to increased unsaturation of milk fat (Palmquist et al., 1993). However, in this study, fermentor $\mathrm{pH}$ did not differ for the corn and barley diets (Table 3).

The effects of monensin and SBO on C18:1 and C18:2 differed depending on grain source. When the grain source was corn, monensin and SBO only had an effect on C18:1 when the two additives were combined (Figure $3 \mathrm{~A})$. The opposite occurred for the barley diet. Monensin or SBO alone increased $(P<0.05) \mathrm{C} 18: 1$, but the combination of monensin and SBO had no effect on C18:1 concentration. In the case of C18:2, monensin and SBO alone or in combination all reduced $(P<0.05)$ C18:2 when the grain source was corn. But when the grain source was barley, only the combination of monensin and SBO reduced $(P<0.05) \mathrm{C} 18: 2$ in the cultures $($ Figure $3 \mathrm{~B})$. These results suggest that monensin and fat additives are likely to reduce or have little effect on unsaturated FA concentration in ruminal contents when corn is the primary starch source. However, monensin and SBO could increase unsaturated FA concentration in the rumen if grains with higher rates of digestion are present in the diet, such as barley.

Among the trans FA, total trans C18:1 concentration in the fermentor contents was higher $(P<0.05)$ for
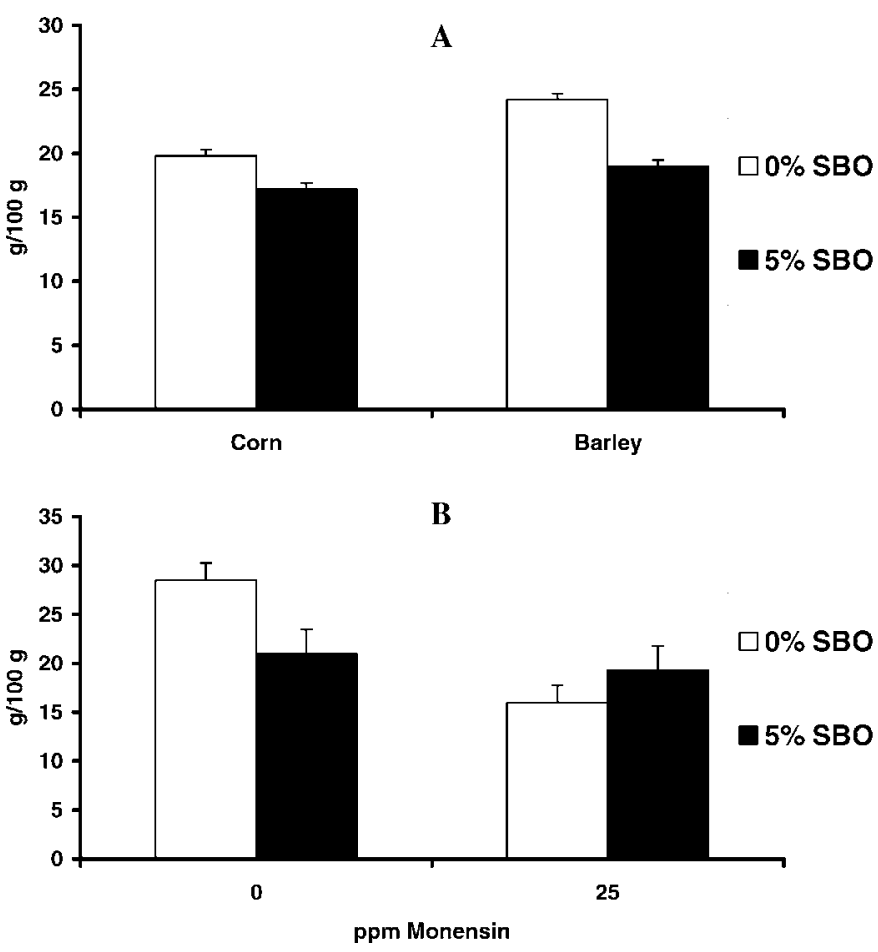

Figure 2. A) The grain source by soybean oil (SBO) interaction on $\mathrm{C} 16: 0$ and $\mathrm{B}$ ) the monensin (M) by SBO interaction on C18:0 concentrations in cultures of mixed ruminal microbes grown in continuous fermentors. Error bars are pooled SEM. 

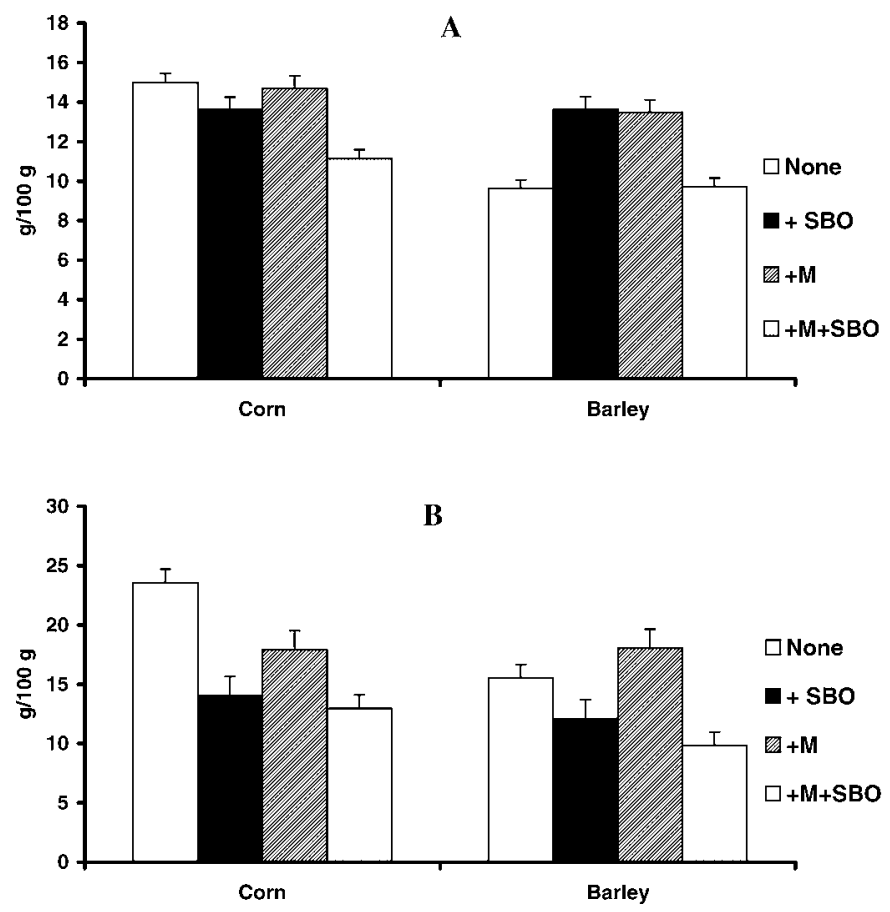

Figure 3. The grain source by monensin (M) by soybean oil (SBO) interactions for A) C18:1 and B) C18:2 concentrations in cultures of mixed ruminal microbes grown in continuous fermentors. Error bars are pooled SEM.

corn compared to barley (Table 4). Total trans C18:1 concentration increased $(P<0.05)$ when either monensin or SBO was added to the fermentors. The addition of SBO increased total trans C18:1 isomers nearly 100\%, compared to a $53 \%$ increase caused by the addition of monensin. The concentration of total CLA isomers was not affected by monensin or SBO, but was lower $(P<$ $0.05)$ for the barley diet compared to the corn diet. The three treatments each affected a different CLA isomer. The barley diet had a lower $(P<0.05)$ cis-9, trans11 C18:2 concentration than the corn diet, monensin decreased $(P<0.05)$ trans-9, trans-11 C18:2; and SBO increased $(P<0.05)$ trans-10, cis-12 C18:2.

The treatments also changed the concentration of individual trans mononene isomers present in the fermentor contents (Table 4). The addition of SBO increased $(P<0.05)$ trans-12 $\mathrm{C} 18: 1$ and trans-10 C18:1 concentrations, but reduced $(P<0.05)$ the concentration of trans-11 C18:1. Monensin increased $(P<0.05)$ trans$10 \mathrm{C} 18: 1$ isomer but had no effect on the concentration of the trans-11 or trans-12 isomers. The only trans C18:1 isomer affected by grain source was trans-11, which was higher $(P<0.05)$ for corn than for barley. The trans-6 C18:1 isomer was not affected by any treatment. Therefore, the majority of the increases in trans C18:1

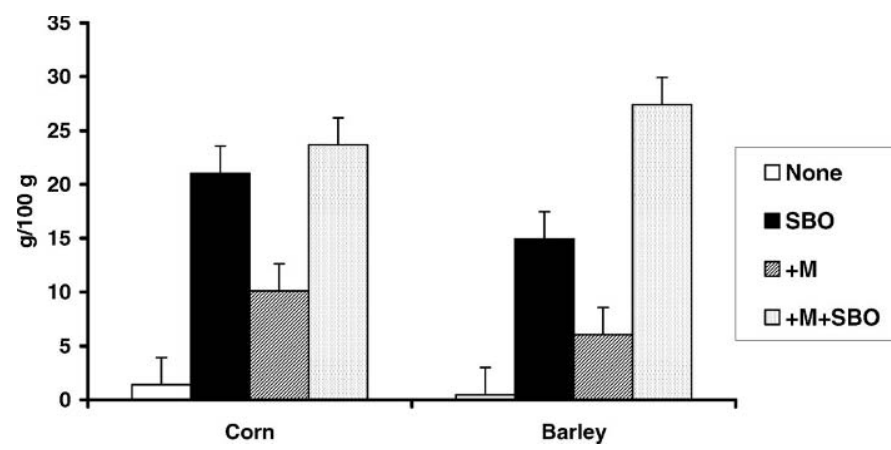

Figure 4. The grain source by monensin (M) by soybean oil (SBO) interactions for trans-10 C18:1 concentration in cultures of mixed ruminal microbes grown in continuous fermentors. Error bars are pooled SEM.

by monensin and SBO could be attributed to an increase in a single isomer, i.e., trans-10 C18:1.

The only treatment interaction among the trans FA was for trans-10 C18:1. Adding monensin or SBO individually to the fermentors increased $(P<0.05)$ trans$10 \mathrm{C} 18: 1$ concentration, with a greater increase for SBO (Figure 4). However, when monensin and SBO were combined, trans-10 C18:1 concentration increased, but only when the grain source was barley. For the corn diet, the trans-10 C18:1 concentration in the fermentors was similar for SBO and the combination of monensin and SBO. The three-way interaction for trans-10 C18:1 has implications on milk fat depression in lactating dairy cows. Among the CLA isomers, the presence of a trans-10 double bond appears to be required for depression of milk fat synthesis. Earlier studies showed that infusion of trans-10, cis-12 C18:2 into the abomasum of lactating dairy cows led to a 42 to $44 \%$ reduction in milk fat (Baumgard et al., 2000), but abomasal infusion of cis-9, trans-11 C18:2 did not affect milk fat percentage. If the presence of a trans-10 double bond in monenes similarly reduces milk fat synthesis, then combining monensin with fat in dairy rations could reduce milk fat percentage considerably more than feeding either monensin or fat alone.

The question remains as to why the monensin-fat combination increased trans-10 C18:1 concentration the most only when the grain source was barley. Barley contains 57 to $58 \%$ starch compared to $72 \%$ starch in corn (Huntington, 1997), but the degradability of starch in barley is higher than corn (Herrera-Saldana, 1990). Increasing starch at the expense of fiber in ruminant diets reduces the numbers of lipolytic bacteria in the rumen (Latham et al., 1972) and the rates of lipolysis and biohydrogenation (Gerson et al., 1985). Although starch content was lower for the barley diet, perhaps the higher degradability of the starch interfered with 
the completeness of biohydrogenation causing accumulation of the trans intermediates. If this occurred, it cannot be attributed to low $\mathrm{pH}$ conditions in the fermentors because fermentor $\mathrm{pH}$ was the same for both grain sources (Table 3). Instead, perhaps the higher starch degradability of barley caused a shift in the microbial species associated with the completeness of biohydrogenation, namely the Group B bacteria (Jenkins, 1993). Ruminal microorganisms capable of fatty acid hydrogenation are often divided into Groups A and B based on their end-products and patterns of isomerization during biohydrogenation (Harfoot and Hazelwood, 1988). Bacterial species in Group A hydrogenate linoleic acid to trans C18:1 but appear incapable of hydrogenating mononenes. Group B bacteria can hydrogenate a wide range of monenes, including trans-11 C18:1, to stearic acid.

\section{CONCLUSIONS}

Monensin and SBO were added to continuous cultures of mixed ruminal microorganisms in this study to determine how they affected trans fatty acid concentrations when added singly or in combination. Among several isomers of trans mononenes and CLA that were examined, the monensin and SBO increased the concentration of the trans-10 C18:1 isomer the most. Also, combining monensin and SBO increased trans-10 C18:1 more than either additive alone but only if the grain source was barley. The results of this study suggest that the source of starch supplied in high grain diets can accentuate the ability of antimicrobial agents, such as ionophores and unsaturated fatty acids, to disrupt biohydrogenation and increase selected trans FA in the rumen. Because some trans fatty acid isomers have been associated with milk fat depression in dairy cows, these results suggest that monensin and plant oils fed together in dairy rations can depress milk fat percentage more severely than either additive alone, particularly in diets high in rapidly-fermentable starch sources, such as barley.

\section{ACKNOWLEDGMENTS}

Approved as technical contribution no. 4758 of the South Carolina Agricultural Experiment Station, Clemson University. Additional support was provided by Elanco Animal Health, Indianapolis, IN.

\section{REFERENCES}

Bateman II, H. G., and T. C. Jenkins. 1998. Influence of soybean oil in high fiber diets fed to nonlactating cows on ruminal unsaturated FA and nutrient digestibility. J. Dairy Sci. 81:2451-2458.

Baumgard, L. H., B. J. Corl, D. A. Dwyer, A. Saebo, and D. E. Bauman. 2000. Identification of the conjugated linoleic acid isomer that inhibits milk fat synthesis. Am. J. Physiol. Regulatory Integrative Comp. Physiol. 278:R179-R184.

Beecher, G. R., and B. K. Whitten. 1970. Ammonia determination: reagent modification and interfering compounds. Anal. Biochem. $36: 243-246$

Bessa, R. J. B., J. Santos-Silva, J. M. R. Ribeiro, and A. V. Portugal. 2000. Reticulo-rumen biohydrogenation and the enrichment of ruminant edible products with linoleic acid conjugated isomers. Livest. Prod. Sci. 63:201-211.

Fellner, V., F. D. Sauer, and J. K. G. Kramer. 1995. Steady-state rates of linoleic acid biohydrogenation by ruminal bacteria in continuous culture. J. Dairy Sci. 78:1815-1823.

Fellner, V., F. D. Sauer, and J. K. G. Kramer. 1997. Effect of nigericin, monensin, and tetronasin on biohydrogenation in continuous flow-through ruminal fermentors. J. Dairy Sci. 80:921-928.

Gerson, T., A. John, and A.S.D. King. 1985. The effects of dietary starch and fiber on the in vitro rates of lipolysis and hydrogenation by sheep rumen digesta. J. Agric. Sci., Camb. 105:27-30.

Griinari, J. M., D. A. Dwyer, M. A. McGuire, D. E. Bauman, D. L. Palmquist, and K.V.V. Nurmela. 1998. Trans-octadecenoic acids and milk fat depression in lactating dairy cows. J. Dairy Sci. 81:1251-1261.

Harfoot, C. G. and G. P. Hazelwood. 1988. Lipid metabolism in the rumen. In The Rumen Microbial Ecosystem. P. N. Hobson, ed. Elsevier Science Publishing, New York, NY. 285-322.

Herrera-Saldaña, R., R. Gomez-Alarcón, M. Torabi, and J. T. Huber. 1990. Influence of synchronizing protein and starch degradation in the rumen on nutrient utilization and microbial synthesis. J. Dairy Sci. 73:142-148.

Huntington, G. B. 1997. Starch utilization by ruminants: from basics to bunk. J. Anim. Sci. 75:852-867.

Jenkins, T. C. 1993. Lipid metabolism in the rumen. J. Dairy Sci. 76:3851-3863.

Kramer, J. K. G., V. Fellner, M. E. R. Dugan, F. D. Sauer, M. M. Mossoba, and M. P. Yurawecz. 1997. Evaluating acid and base catalysts in the methylation of milk and rumen FA with special emphasis on conjugated dienes and total trans fatty acids. Lipids 32:1219-1228.

Latham, M. J., J. E. Storry, and M. E. Sharpe. 1972. Effects of lowroughage diets on the microflora and lipid metabolism in the rumen. Appl. Microbiol. 24:871-877.

Palmquist, D. L., A. D. Beaulieu, and D. M. Barbano. 1993. Feed and animal factors influencing milk fat composition. J. Dairy Sci. 76:1753-1771.

Pantoja, J., J. L. Firkins, M. L. Eastridge, and B. L. Hull. 1996. Fatty acid digestion in lactating dairy cows fed fats varying in degree of saturation and different fiber sources. J. Dairy Sci. 79:575-584.

SAS $\odot$ System for Windows. Version 8. 1999. SAS Inst., Inc., Cary, NC.

Sauer, F. D., V. Fellner, R. Kinsman, J. K. G. Kramer, H. A. Jackson, A. J. Lee, and S. Chen. 1998. Methane output and lactation response in Holstein cattle with monensin or unsaturated fat added to the diet. J. Anim. Sci. 76:906-914.

Van Nevel, C., and D. I. Demeyer. 1995. Lipolysis and biohydrogenation of soybean oil in the rumen in vitro: Inhibition by antimicrobials. J. Dairy Sci. 78:2797-2806.

Van Nevel, C. J., and D. I. Demeyer. 1996. Influence of $\mathrm{pH}$ on lipolysis and biohydrogenation of soybean oil by rumen contents in vitro. Reprod. Nutr. Dev. 36:53-65.

Vasquez-Anon, M., T. Cassidy, P. McCullough, and G. A. Varga. 2001. Effects of alimet on nutrient digestibility, bacterial protein synthesis, and ruminal disappearance during continuous culture. J. Dairy Sci. 84:159-166. 